\title{
Diffusion length measurements of microcrystalline silicon thin films prepared by hot-wire/catalytic chemical vapor deposition (HWCVD)
}

\author{
S. Okur ${ }^{\mathrm{a}, *}$, M. Güneş ${ }^{\mathrm{a}}$, F. Finger ${ }^{\mathrm{b}}$, R. Carius ${ }^{\mathrm{b}}$ \\ a Izmir Institute of Technology, Department of Physics, Gülbahçe, Urla, Izmir TR-35430, Turkey \\ b Institut für Photovoltaik, Forschungszentrum Jülich GmbH, 52425 Jülich, Germany
}

Available online 11 August 2005

\begin{abstract}
Hydrogenated microcrystalline silicon ( $\mu \mathrm{c}-\mathrm{Si}: \mathrm{H})$ films prepared by using the hot-wire/catalytic chemical vapor deposition (HWCVD) technique at low substrate temperatures between $185^{\circ} \mathrm{C}$ and $220^{\circ} \mathrm{C}$ with different silane concentrations (SC) were investigated using steadystate photocarrier grating (SSPG) and the steady-state photoconductivity methods (SSPC). Crystalline volume fractions $\left(I_{\mathrm{C}}^{\mathrm{RS}}\right)$ obtained from Raman spectroscopy change from 0.22 to 0.77 . The diffusion length $\left(L_{\mathrm{D}}\right)$ is measured at generation rates between $G=10^{19}$ and $10^{21} \mathrm{~cm}^{-3}$ $\mathrm{s}^{-1} . L_{\mathrm{D}}$ changes from $27 \mathrm{~nm}$ to $270 \mathrm{~nm}$, with maximum values around $\mathrm{SC}=5 \%$. The dependence of $L_{\mathrm{D}}$ on $\mathrm{SC}$ is similar to that observed for similar quality microcrystalline silicon films prepared using the VHF-PECVD technique. The grating quality factor, $\gamma_{0}$, drops from about 0.9 to 0.5 after transition to the microcrystalline regime as indication of scattering from surface patterns.
\end{abstract}

(C) 2005 Elsevier B.V. All rights reserved.

Keywords: Raman spectroscopy; Hot-wire/catalytic chemical vapor deposition; Diffusion length; Steady-state photocarrier grating

\section{Introduction}

Hot-wire chemical vapor deposition (HWCVD) processes have become one of the powerful techniques in producing microcrystalline silicon ( $\mu \mathrm{c}-\mathrm{Si}: \mathrm{H})$ material with a precise control on the crystalline volume fraction of solar cell films in the past few years $[1-3]$. Recent experimental results on $\mu \mathrm{c}-\mathrm{Si}: \mathrm{H}$ materials produced by this technique show that the best solar cell performance is obtained in a microcrystalline growth regime close to the transition to amorphous growth conditions $[3,4]$. Crystalline volume fraction on these types of films is usually inferred from Raman spectroscopy for structural analysis [5]. Steady-state photocarrier grating method (SSPG) and steady-state photoconductivity (SSPC) methods have been used for the characterization of both minority and majority carrier transport properties of a-Si:H and $\mu \mathrm{c}-\mathrm{Si}: \mathrm{H}$ films or materials between these two regimes [6-8]. A correlation between electronic properties and

\footnotetext{
* Corresponding author.

E-mail addresses: salihokur@iyte.edu.tr, okursalih@hotmail.com (S. Okur).
}

structural properties related with deposition conditions around the transition region from $\mu \mathrm{c}-\mathrm{Si}: \mathrm{H}$ to a-Si:H growth is an important issue to improve solar cell efficiency.

In this work, we investigate the relationship between diffusion length measured with SSPG experiments and crystalline volume fractions obtained from Raman Spectroscopy on the $\mu \mathrm{c}-\mathrm{Si}: \mathrm{H}$ films, which were selected from various silane concentrations, ranging from highly crystalline to nearly amorphous, prepared by the HWCVD technique.

\section{Experimental details}

Undoped hydrogenated microcrystalline silicon ( $\mu \mathrm{c}-$ $\mathrm{Si}: \mathrm{H})$ films were fabricated by using the hot-wire/catalytic chemical vapor deposition (HWCVD) technique with tantalum filaments at temperatures between $1650{ }^{\circ} \mathrm{C}$ and $1800{ }^{\circ} \mathrm{C}$, substrate temperatures between $185^{\circ} \mathrm{C}$ and 220 ${ }^{\circ} \mathrm{C}$, and with different silane concentrations, $\mathrm{SC}\left(=\left[\mathrm{SiH}_{4}\right] /\right.$ $\left.\left[\mathrm{SiH}_{4}+\mathrm{H}_{2}\right]\right)$, by varying the flow ratio of silane and hydrogen gas between $2 \%$ and $10 \%$. The films were deposited on glass substrates (Corning 7059 and/or Corning 


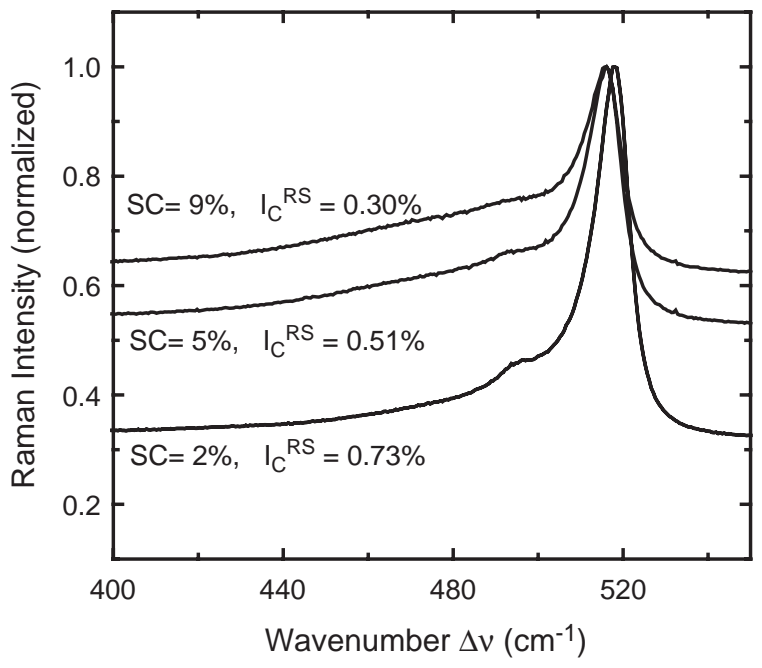

Fig. 1. Raman intensity versus wave number between 400 and $540 \mathrm{~cm}^{-1}$ from samples prepared in the transition region from microcrystalline to amorphous growth using the SCs from $2 \%$ to $9 \%$.

1737) with a film thickness between $520 \mathrm{~nm}$ and $965 \mathrm{~nm}$ on a substrate area of $10 \times 10 \mathrm{~cm}^{2}$. The total gas pressure was changed between $3 \mathrm{~Pa}$ and $20 \mathrm{~Pa}$ to create different crystalline volume fractions changing from amorphous to crystalline regime. The substrates were partly covered with $100 \mathrm{~nm}$ electron beam evaporated chromium films before each deposition to cutoff contribution from the glass for the Raman measurements.

The experimental configuration for the SSPG technique is given in previous reports [6,7]. In the SSPG experiment, one measures the ratio $\beta$ of the ac photocurrents with and without the grating created by two coherent laser beams due to interference fringes (inhomogeneous photocarrier distribution regions) between electrodes of a sample by changing the grating period, $\Lambda$, defined as $\Lambda=\lambda /[2 \sin (\theta / 2)]$, where $\lambda$ is the laser wavelength and $\theta$ is the angle between the two incoming laser beams. The diffusion length $L_{\mathrm{D}}$ and grating quality fitting parameter $\phi$ are obtained from $\beta$ versus $\Lambda$ plots by using nonlinear least square fit to the following SSPG equation:

$\beta=1-\frac{2 \phi}{\left[\left(1+\left(\frac{2 \pi L_{\mathrm{D}}}{\Lambda}\right)^{2}\right)\right]^{2}}$.

The SSPG grating quality factor $\gamma_{0}$ is calculated from $\gamma_{\mathrm{o}}=\left(\phi / \gamma_{\mathrm{d}} \gamma\right)^{1 / 2}$, where $\phi$ is the SSPG fitting parameter obtained from the fit to experimental $\beta$ versus $\Lambda$ curve, $\gamma$ is the exponent of the photoconductivity $\sigma_{\mathrm{ph}}$ vs. generation rate $G$, and $\gamma_{\mathrm{d}}$ is the dark conductivity reducing factor defined as $\gamma_{\mathrm{d}}=\sigma_{\mathrm{ph}} /\left(\sigma_{\mathrm{ph}}+\sigma_{\text {dark }}\right)[7,8]$. The quality factor $\gamma_{\mathrm{o}}$ is a measure of light scattering from rough surface and other imperfections of the experimental setup or the samples themselves.

A He-Ne Laser with a wavelength of $633 \mathrm{~nm}$ was used to measure small-signal photocurrents at $10 \mathrm{~V}$ dc bias voltage between the coplanar contacts with a gap of $0.5 \mathrm{~mm}$ of $\mu \mathrm{c}-\mathrm{Si}: \mathrm{H}$ samples using a Stanford Research lock-in amplifier SR 830. All the steady-state grating conditions given in the Ref. [7] have been satisfied in the present work.

\section{Results and discussion}

The Raman scattering experiment was performed using $488 \mathrm{~nm}$ laser light. In Fig 1, Raman intensity as a function of wave number between 400 and $540 \mathrm{~cm}^{-1}$ is shown for $\mu \mathrm{c}-\mathrm{Si}: \mathrm{H}$ samples prepared in the transition region between $\mathrm{SC}$ from $2 \%$ to $9 \%$. The crystalline volume fraction $\left(I_{\mathrm{C}}^{\mathrm{RS}}\right)$ was calculated from integrated intensity ratio,

$I_{\mathrm{C}}^{\mathrm{RS}}=\left(I_{520}+I_{500}\right) /\left(I_{520}+I_{500}+I_{480}\right)$,

by de-convolution of the spectral data into three characteristic Gaussian peaks representing amorphous phase at 480 $\mathrm{cm}^{-1}$, grain boundary phase at $500 \mathrm{~cm}^{-1}$ and crystalline contribution at $520 \mathrm{~cm}^{-1} . I_{\mathrm{C}}^{\mathrm{RS}}$ is used as a semiquantitative measure of the crystalline volume fraction.

In Fig. 2, the photocurrents ratio $\beta$ is plotted versus the grating period $\Lambda$. The diffusion length $L_{\mathrm{D}}$ and the grating quality factor $\phi$ are obtained from a nonlinear least square fit to the function defined in Eq. (1). The $L_{\mathrm{D}}$ values obtained for the intrinsic $\mu \mathrm{c}-\mathrm{Si}: \mathrm{H}$ films are shown in Fig. $3 \mathrm{a}$ as a function of $\mathrm{SC}$, where $L_{\mathrm{D}}$ shows a maximum around $\mathrm{SC}$ of $5 \%$. It is important to note that the set of intrinsic $\mu \mathrm{c}-\mathrm{Si}: \mathrm{H}$ films studied here originates from slightly different deposition parameters such as substrate temperature and pressure. Therefore, $\mathrm{SC}$ is not the only parameter to determine the microstructure of these films. For this reason, crystalline volume fraction, $I_{\mathrm{C}}^{\mathrm{RS}}$, is used to compare the effects of microstructure on the $L_{\mathrm{D}}$ values. In Fig. $3 \mathrm{~b}$, the diffusion length is shown as a function of $I_{\mathrm{C}}^{\mathrm{RS}}$ evaluated from the Raman data obtained around the transition growth region

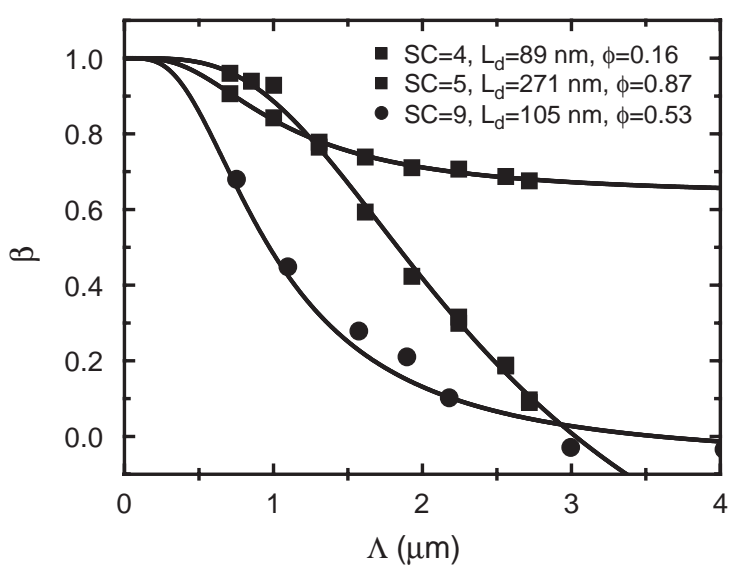

Fig. 2. Photocurrent ratio $\beta$ versus grating period ( $\Lambda$ ) for SC from $4 \%$ to $9 \%$. The lines are nonlinear least square fits to the function defined in Eq. (1). $L_{\mathrm{D}}$ (diffusion length) and $\phi$ (grating quality parameter) are the fitting parameters. 
from amorphous to microcrystalline. The diffusion length appears to have a maximum around $I_{\mathrm{C}}^{\mathrm{RS}}$ of 0.5 and then decreases with higher crystalline volume fraction. The highest $L_{\mathrm{D}}$ of $271 \mathrm{~nm}$ and the highest grating quality factor $\gamma_{0}$ of 0.96 is obtained for the sample prepared with the lowest substrate temperature of $185{ }^{\circ} \mathrm{C}$, with SC of $5 \%$ and $I_{\mathrm{C}}^{\mathrm{RS}}$ of 0.51 , with the total gas pressure of $3.5 \mathrm{~Pa}$. A possible reason for low values of diffusion length at highly crystalline region might be due to increasing defect density created by hydrogen dilution on the walls of individual columnar microcrystalline grains inside the structure [9]. However, low diffusion length for the amorphous films is attributed to defect states related with unsaturated silicon dangling bonds (DB).

In addition, the effect of microstructure due to changing SC and other deposition parameters is also obtained from the grating quality factor $\phi$. Most of the high quality microcrystalline silicon films do not exhibit a perfect
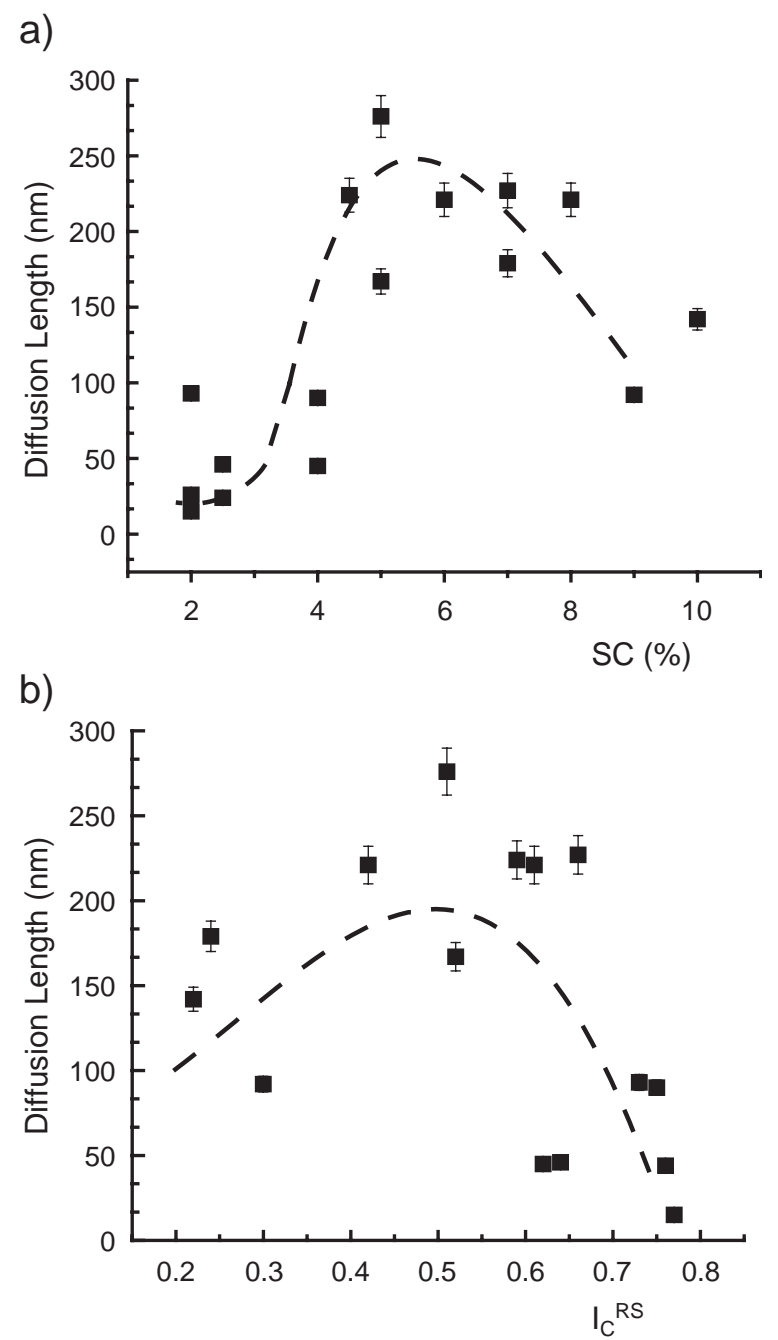

Fig. 3. (a) Diffusion length versus SC. The dashed lines are guides to the eye only. (b) Diffusion length versus $I_{\mathrm{C}}^{\mathrm{RS}}$ obtained from Raman data for the films prepared in the transition growth regime with SC between $2 \%$ and $8 \%$. The dashed line is a guide to the eye.

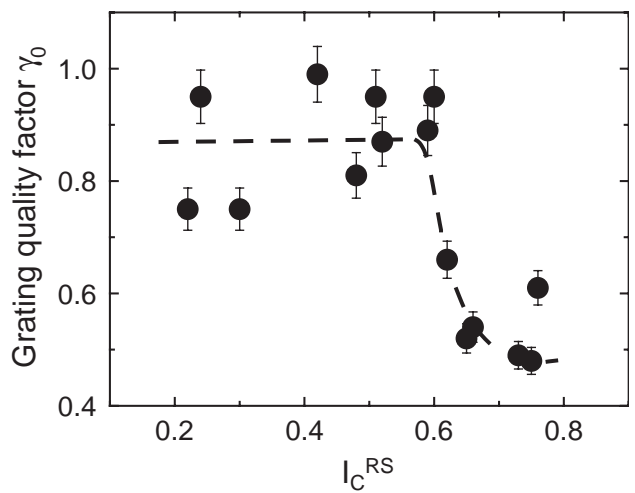

Fig. 4. Grating quality factor $\gamma_{0}$ versus crystalline volume fraction, $I_{\mathrm{C}}^{\mathrm{RS}}$.

mirror-like surface. Surface scattering has been shown to decrease the grating quality fit parameter $\phi$ in SSPG experiments [10]. The effect of the crystalline volume fraction $I_{\mathrm{C}}^{\mathrm{RS}}$ on the grating quality factor $\gamma_{0}$ is shown in Fig. 4. In the amorphous and low crystalline region, $\gamma_{\mathrm{o}}$ values are around 0.9 and decrease to 0.5 after the transition to the microcrystalline growth regime. The smaller values of the grating quality factor $\gamma_{0}$ most probably result from light scattering from nano-crystalline patterns on the surface of $\mu \mathrm{c}-\mathrm{Si}: \mathrm{H}$ films at the highly crystalline region prepared by HWCVD technique.

\section{Summary}

Intrinsic microcrystalline silicon thin films were prepared by the HWCVD technique with various silane concentrations. Crystalline volume fractions $I_{\mathrm{C}}^{\mathrm{RS}}$ change from 0.22 to 0.77 for SC between $10 \%$ and $2 \%$, respectively, obtained from Raman scattering. The diffusion length $L_{\mathrm{D}}$ shows a maximum value of $271 \mathrm{~nm}$ around $\mathrm{SC}=5 \%$ and corresponding $I_{\mathrm{C}}^{\mathrm{RS}}$ of 0.51 for the sample with lowest substrate temperature of $185{ }^{\circ} \mathrm{C}$ and then decreases with increasing $I_{\mathrm{C}}^{\mathrm{RS}}$ probably as a result of the increasing defect density originating from the unsaturated dangling bonds in the amorphous region and defects on the wall of grains due to the etching effect of hydrogen dilution in highly crystalline region. The grating quality factor $\gamma_{0}$ decreases substantially from 0.9 to 0.5 after transition to the microcrystalline regime indicating the effects of light scattering from surface patterns of high crystalline intrinsic films.

\section{Acknowledgements}

The authors thank R. Brüggemann for stimulating discussions on improving the SSPG methods for investigation of $\mu \mathrm{c}-\mathrm{Si}: \mathrm{H}$ thin films and O. Göktaş for helping on photoconductivity measurements. This joint project is partially supported by the International Bureau of the BMBF, Germany and The Scientific and Technical Research 
Council of Turkey (TÜBİTAK) under the project number TBAG-U/14 (101T016).

\section{References}

[1] S. Klein, PhD. Thesis, Technische Universität München, Germany, 2004.

[2] C. Niikura, S.Y. Kim, B. Drévillon, Y. Poissant, P. Roca i Cabarrocas, J.E. Bourée, Thin Solid Films 395 (2001) 178.

[3] S. Klein, F. Finger, R. Carius, B. Rech, L. Houben, M. Luysberg, M. Stutzmann, Mater. Res. Soc. Symp. Proc. 715 (2002) A26.2.
[4] C. Niikura, Y. Poissant, M.E. Gueunier, J.P. Kleider, J.E. Bourée, J. Non-Cryst. Solids 299-302 (2002) 1179.

[5] L. Houben, M. Luysberg, P. Hapke, R. Carius, F. Finger, H. Wagner, Philos. Mag., A 77 (1998) 1447.

[6] R. Ritter, E. Zelodov, K. Weiser, J. Appl. Phys. 62 (1987) 4563.

[7] S. Okur, M. Güneş, O. Göktaş, F. Finger, R. Carius, J. Mater. Sci., Mater. Electron. 15 (2004) 187.

[8] M. Goerlitzer, N. Beck, P. Torres, J. Meier, N. Wyrsch, A. Shah, J. Appl. Phys. 80 (1996) 5111.

[9] F. Finger, S. Klein, T. Dylla, A.L. Baia Neto, O. Vetterl, R. Carius, Mater. Res. Soc. Symp. Proc. 715 (2002) A16.3.

[10] R. Brüggemann, Appl. Phys. Lett. 73 (1998) 499. 